\title{
Learning volition: a longitudinal study of developing intentional awareness in Tourette syndrome
}

\begin{abstract}
Tourette syndrome (TS) is characterized by the presence of involuntary movements (tics) which are, at least partly, generated within 'voluntary' motor pathways. Here we reassess 16 TS patients (age 19 \pm 2.3 years) who participated in a mental chronometry study of volition 5.5 years previously (Ganos C et al. Cortex. 2015 Mar;64:47-54), and 16 age-matched controls. Participants estimated the time of their own voluntary movements (Libet's M judgement), or of conscious intention to make voluntary movements (Libet's W judgement), in separate blocks. We considered M judgement as a control condition. Therefore, the experience of an intention to move occurring prior to actual movement onset, as measured by the W-M gap, was taken as the cardinal feature of volition.

Time estimates of the TS group did not differ significantly from controls, for either M or W judgement. Further, $\mathrm{M}$ and $\mathrm{W}$ time estimates in the TS group had not changed significantly between the two assessments. However, exploratory analyses revealed a strong relation between disease duration and the development of $\mathrm{M}$ - and $\mathrm{W}$-judgements: the longer was the disease duration, the less was the developmental increase in the W-M gap (linear regression, $\mathrm{p}=0.003$ ). In conclusion, our results suggest compromised development of experience of volition in developing TS patients. The developmental difficulty in processing internal premotor signals for voluntary actions could reflect the chronic persistence of tics from adolescence to adulthood.
\end{abstract}




\section{Introduction}

The idea that we control our own actions is a cornerstone of modern views of human nature. This idea translates to a view of volitional action control as a central function of the human brain in everyday life, at least for healthy adults. However, the definition of what makes a movement voluntary is controversial (Haggard, 2008). On one account, motor behaviors lie along a continuum between voluntary and involuntary. Accordingly, voluntary actions are movements that are typically accompanied by a conscious experience of deciding to act, an effortful sense of "doing", and a sense of agency (Haggard, 2017), while involuntary movements typically occur effortlessly (Ganos, Pareés, et al., 2015) and are experienced as independent of the subject's mental activity. For example, one can sometimes be surprised by a spontaneously-occurring involuntary movement, while one's own voluntary movements are not surprising. The classic study of Libet at al. (Libet et al., 1983) indicated a distinctive experience of conscious intention that preceded voluntary action by some $200 \mathrm{~ms}$. Involuntary movements are not accompanied by these experiences of conscious intention (Keller \& Heckhausen, 1990). Voluntary and involuntary movements indeed produce very different perceptual experiences (Haggard et al., 2002). This is not due to differences in the afferent signals generated by the movement (Ghosh \& Haggard, 2014), but to differences in the efferent motor signals (Wolpert \& Flanagan, 2001). The cognitive processes that drive efferent motor commands for voluntary action appear to generate a distinctive experience that predicts the action itself.

Such predictive action-related signals are key to understanding a class of neuropsychiatric disorders, notably schizophrenia, whose hallmark feature is altered perception of one's own actions (Frith, 1987; Poletti et al., 2017). Surprisingly, however, the voluntary-involuntary continuum has rarely been used experimentally to investigate those neuropsychiatric conditions that manifest as hyperkinetic movement disorders, such as tic disorders and Tourette syndrome (TS) (Delorme et al., 2016; Ganos, Asmuss, et al., 2015; Moretto et al., 2011). The hallmark of 
these disorders is an excess of brief, repetitive movements, generated by voluntary motor pathways, but perceived as involuntary (Ganos \& Martino, 2015). These involuntary movements have strong detrimental effects on psychosocial functioning (Eapen et al., 2016). Thus, the scientific questions regarding what makes actions voluntary are not only of philosophical interest, but are also relevant to clinical judgement, and, ultimately, to the individuals' quality of life.

TS is a neurodevelopmental disorder. Tics typically appear during early development and are often first noted in children aged 4-6 years. However, they may already occur within the first years of life in parallel with the emergence of voluntary actions (Bloch \& Leckman, 2009; Sambrani et al., 2016). In many cases, tics also persist into adulthood (Bloch \& Leckman, 2009; Groth et al., 2017). There is often behavioral overlap between voluntary actions or involuntary tics: tics frequently involve well-structured motor actions, including gestures, gait patterns and utterances (Ganos et al., 2014). This raises an intriguing question of what processes, within the developing nervous system, determine whether any individual movement is experienced as voluntary or as involuntary.

Using the classic method of mental chronometry (Libet et al., 1983), we have previously investigated clinical predictors of conscious intention to act in a sample of adolescents with TS and healthy controls (aged 10-17 years). In this method, participants are asked to make simple voluntary movements, at a time of their own choosing. They use a rotating clock hand to judge either the time of the movement itself (Libet's M judgement), or the time of the experience of the conscious intention to make the movement (Libet's $\mathrm{W}$ judgement). The experience of intention typically precedes the experience of movement (i.e. there is a W-M gap) by hundreds of ms. Our findings in TS adolescents suggested that the experience of volition relies on perceptual detection of premotor signals that are experienced as conscious intentions (Ganos, Asmuss, et al., 2015). We speculated that extended perceptual learning throughout development is required for these signals to be successfully discriminated: people learn in childhood to 
experience their own volition, and thus to become voluntary agents. However, if excessive unintended actions are present, as in tic disorders (Mink, 2001), then perceiving and identifying the distinct qualities of intentional action may be impaired. In other words, increased levels of neuromotor noise in TS could affect the process of perceptual learning of intentions.

This conclusion was based on a cross-sectional comparison between TS adolescents to agematched controls. However, theories about learning and development conventionally require longitudinal testing. Therefore, we have performed the first longitudinal experimental study examining the development of volition, with a subgroup of TS patients who participated in the original study, 5.5 years previously (Ganos, Asmuss, et al., 2015). We also recruited a group of 16 healthy controls to provide cross-sectional data for age-matched comparisons at the second time point. Our previous hypothesis based on perceptual learning of volitional signals predicts that the time of conscious intention should shift earlier between the first and second time point - specifically, the W-M gap should increase - but only to the extent that involuntary motor noise due to tics reduces over this period.

\section{Material and methods}

We report how we determined our sample size, all data exclusions, all inclusion/ exclusion criteria, whether inclusion/ exclusion criteria were established prior to data analysis, all manipulations, and all measures in the study.

Twenty-seven patients diagnosed with TS who had participated in a previous study (Ganos, Asmuss, et al., 2015) were followed-up via telephone. Of those, 16 patients (14 male, age $19 \pm$ 2.3 years, range $15-22$ years, see table 1) agreed to participate in the current study. The 11 patients lost to follow-up had similar age $(13.9 \pm 2.4$ years $)$, disease severity (Yale Global Tic Severity Scale, YGTSS-100, $25.5 \pm 15.3$ ) and premonitory urges (Premonitory Urges for Tics Scale, PUTS, $20.1 \pm 7.2$ ) at T1, when compared to those who agreed to participate in the present follow-up study. The disease related quality of life of TS patients that did not participate in the 
follow-up study was lower at T1 (Gilles de la Tourette-Quality of Life-Questionnaire, GTSQoL, $14.3 \pm 21.3$, compare to table 1), compared to those who did participate. An age-matched control group $(\mathrm{n}=16 ; 11$ male, age $19.1 \pm 2.6$ years, range $14-24$ years, see table 1$)$ was recruited anew, as we found that few healthy subjects from T1 were available for this study. Exclusion criteria, which were defined prior to execution of the study, were the inability to understand the experimental instructions for both groups, and, additionally, a history of tics and a history of tics in first-degree relatives for healthy controls. All subjects, and in case of minors also their parents, gave written informed consent prior to the study. The study was performed in accordance with the Declaration of Helsinki and was approved by the local ethics committee of the University Medical Center Hamburg-Eppendorf (PV5362) between June 2017 and January 2018. The study procedures and the study analyses were not pre-registered prior to the research being conducted. No data was excluded prior to analysis.

All clinical assessments were conducted by two experienced examiners (TM, CG). Current tic severity was evaluated using the Yale Global Tic Severity Scale (Leckman et al., 1989). Video recordings were also captured according to the protocol of the Modified Rush Video Scale (MRVS) (Goetz et al., 1999) in two conditions ("free ticcing", FT, vs. "voluntary tic inhibition", VTI) as previously described (Ganos, Bongert, et al., 2015). Videos were rated independently by two examiners (TM, FB), showing good internal consistency for both conditions (free ticcing condition: Cronbachs $\alpha=0.866$ and 0.89 , tic inhibition condition: Cronbachs $\alpha=0.88$ and 0.885). Based on video analysis, a voluntary tic inhibition potential (IP) was also computed as also previously reported (Ganos, Asmuss, et al., 2015), to capture each patient's capacity to suppress their tics. Standard self-report questionnaires for premonitory urges and quality of life were also used (Woods et al., 2005), GTS-QoL (Cavanna et al., 2008).

We assessed neuropsychiatric comorbidities commonly associated with TS (depression, attention deficit hyperactivity disorder (ADHD) and obsessive-compulsive symptoms/disorder (OCS/OCD)) via the Beck's Depression Inventory (BDI-II, (Beck et al., 1961)), the Conners 
Adult ADHD Rating Scale (CAARS, (Christiansen et al., 2011; Conners et al., 1999)), the ADHD-self rating scale (Kessler et al., 2005), the short-form of the Wender Utah rating scale (WURS, (Retz-Junginger et al., 2002; Ward et al., 1993)) and the Yale-Brown Obsessive Compulsive Scale (YBOCS, (Goodman et al., 1989)).

The experimental set-up was based on that of Libet and colleagues (Libet et al., 1983) and used the same implementation published previously (Ganos, Asmuss, et al., 2015). Experimental code is available via https://doi.org/10.5281/zenodo.3698285. In brief, a small clock hand presented on a computer monitor rotated clockwise on a dial every $2560 \mathrm{~ms}$. Subjects were instructed to press a key at a time of their own choosing [German instruction: Bitte schauen Sie auf die Uhr. Während die Uhr läuft, drücken Sie bitte die Leertaste zu einem selbstgewählten Zeitpunkt. Die Uhr läuft anschließend weiter und stoppt zu einem beliebigen Zeitpunkt.]. Each participant executed the following two conditions: In one condition, participants were instructed to report the position of the clock hand, at which they actually performed the key press (M judgement) [German instruction: Wenn die Uhr stoppt, werden Sie gebeten, die Position des Zeigers anzugeben, als Sie die Leertaste gedrückt haben.]. In the other condition, participants were requested to report the position of the clock hand, at which they felt the urge to move (i.e., press the key, W judgement) [German instruction: Wenn die Uhr stoppt, werden Sie gebeten, die Position des Zeigers anzugeben, als Sie erstmalig den Drang verspürten, diesen anzuhalten]). Two blocks of 40 trials for each condition were executed in a counterbalanced fashion. The means and standard deviations of $80 \mathrm{M}$ judgements and $80 \mathrm{~W}$ judgements were calculated for each participant as previously described (Ganos, Asmuss, et al., 2015). Patients were not given any specific instruction with regard to their tics during the task.

We compared questionnaire data from patients at the two different time points (T1: data from (Ganos, Asmuss, et al., 2015) vs. T2: current data, on average 5.5 years later). Note, that the T1 data reported here is a subset of a dataset reported previously (Ganos, Asmuss, et al., 2015). 
After assessing for normality with the Shapiro-Wilk test, paired t-tests or Wilcoxon signed-rank tests were used accordingly. We also compared demographic and questionnaire data at T2 between the patient and control group. For categorical variables, the Chi-Square test was used. For variables on an interval scale, normality was assessed using the Shapiro-Wilk test, and either unpaired t-tests or Mann-Whitney-U tests were applied. To examine whether intention and action awareness differed between patients and controls at T2, a two-way ANOVA was conducted with group (TS, control) and judgement type (W, M) as independent variables, and mean chronometric judgement error as dependent variable. Because it was an a priori focus of interest, we additionally calculated the W-M gap. We additionally applied an independent samples t-test to assess differences in the $\mathrm{W}-\mathrm{M}$ gap at $\mathrm{T} 2$ between patients and healthy controls. Next, we also investigated whether M- and W-judgements changed over time within the patient group and conducted a repeated-measures ANOVA with judgement type (M, W) and time-point $(\mathrm{T} 1, \mathrm{~T} 2)$ as two two-level factors. We used a paired t-test to assess whether the W-M gap as measure of volition developed between $\mathrm{T} 1$ and $\mathrm{T} 2$ in patients.

In an exploratory analysis, the contribution of disease duration (i.e., period between onset of tics and the current study) to the results was considered. Pearson-correlation coefficients between Libet time estimation data $(\mathrm{M}, \mathrm{W})$ of $\mathrm{T} 1$ and $\mathrm{T} 2$ and disease duration were calculated. A repeated-measures ANOVA with judgement type (M, W) and time-point (T1, T2) as two two-level factors was calculated once more, this time using disease duration as covariate, to distinguish longitudinal effects from disease duration effects. To quantify the disease duration effect more precisely, we performed linear regression using the change in W-M gap between T1 and T2 (i.e., (W2-M2) - (W1-M1)) as the dependent variable, and disease duration as the independent variable.

The correlation of tic severity (YGTSS-100) and the W-M gap at T2 was calculated using Spearman's correlation. Additional linear regression was performed to estimate the influence 
of tic severity on W-M gap. The same calculations were carried out for premonitory urges (PUTS).

In order to evaluate whether volition develops with increasing age, we used linear regression to relate the W-M gap with data from the pooled sample provided by both healthy samples from T1 (Ganos, Asmuss, et al., 2015) and T2. The level of significance was set at $p<0.05$. All statistical analyses were carried out using IBM SPSS Statistics, Version 25. The data that support the findings of this study are available via https://doi.org/10.5281/zenodo.3698285.

\section{Results}

Patient and healthy control data are presented in table 1. Overall, patients scored higher for symptoms related to ADHD and OCD. For patients, there were no significant differences in tic severity or severity rating of premonitory urges between $\mathrm{T} 1$ and $\mathrm{T} 2$ (see table 1, lower panel). As a means to evaluate whether experimental data differed between patients and controls, a two-way analysis of variance (ANOVA) with factors of group (TS, control) and judgement type (W, M) was conducted on the Libet time estimation data at T2. There was no difference between patients and controls $(F(1,30)=0.616, p=0.439)$ and no interaction between group and judgement type $(F(1,30)=0.282, p=0.599)$. Further, an independent samples t-test showed that W-M gaps at T2 did not differ between patients and controls $(t(30)=-0.531, p=0.599$; see figure 1A).

In order to examine whether M- and $\mathrm{W}$-judgements changed over time within the patient group, a repeated-measures ANOVA was conducted. There was an expected significant main effect of condition, reflecting the difference between $\mathrm{W}$ and $\mathrm{M}$ judgements $(F(1,15)=28.421, p<0.001$, $\left.\eta_{p}^{2}=0.655\right)$, but no effect of time-point $\left(F(1,15)=0.000, p=0.99, \eta_{p}^{2}=0.000\right)$ and an interaction that approached trend levels (time*condition, $F(1,15)=2.954, p=0.106, \eta_{p}^{2}=$ 0.165). A paired t-test in the patient group showed a trend for the W-M gap to differ between $\mathrm{T} 1$ and $\mathrm{T} 2(t(15)=-1.719, p=0.106$; see figure $1 \mathrm{~B})$. 
In exploratory analyses, we next investigated possible correlations between clinical parameters of the disease and mental chronometry data. A significant correlation was revealed for disease duration and intention awareness at T2 (W, $r=0.520, p=0.039)$, but not at $\mathrm{T} 1(r=-0.262, p=$ 0.327), nor for $\mathrm{M}$ at either time-point (T1, $r=-0.210, p=0.436, \mathrm{~T} 2, r=0.059, p=0.829$; see figure 1C). To investigate whether controlling for duration of the disease would influence the picture of developing volition, the ANOVA was repeated with disease duration as covariate. Now, a significant main effect of condition $\left(F(1,14)=6.752, p=0.021, \eta_{p}^{2}=0.325\right)$, and also a significant main effect of time $\left(F(1,14)=9.605, p=0.008, \eta_{p}{ }^{2}=0.407\right)$ and a significant interaction (time* condition*disease duration, $F(1,14)=13.236, p=0.003, \eta_{p}{ }^{2}=0.486$ ) were found.

We used linear regression to quantify the underlying relation between disease duration and the development of perceptual discrimination between intention to move and movement itself between T1 and T2 (i.e., the W-M gap) $(t(14)=3.638, p=0.003)$, with $R^{2}=0.486$ (beta $=$ 0.697). That is, the longer the disease duration, the less the developmental increase in the W-M gap (see figure 1D).

Tic severity measured by the YGTSS-100 was not significantly correlated with the W-M gap at T2 $(r=-0.233, p=0.386)$. Linear regression also did not show an influence of tic severity on the W-M gap $(t(14)=-0.768, p=0.455)$. Premonitory urges assessed by PUTS were not significantly correlated with the W-M gap at T2 $(r=-0.006, p=0.983)$, and linear regression did not reveal an influence of the PUTS score on the W-M gap $(t(14)=0.420, p=0.681)$. By pooling the sample of healthy volunteers at T1 from the original study (Ganos, Asmuss, et al., 2015) and the new sample now studied at T2, we were able to test cross-sectionally the effect of age on the W-M gap. A significant positive relation was found $(t(44)=-2.096, p=$ 0.042) with $R^{2}=0.091$ (beta $=-0.301$; i.e., the older the participant, the larger the W-M gap).

\section{Discussion}


This study reports longitudinal data on the development of volition, using mental chronometry in patients with TS. To our knowledge, it is the first longitudinal study of volition. Longitudinal experimental data of the TS patient sample collected 5.5 years apart demonstrated that the main developmental change was a shift to earlier W judgements, and to later M judgements, between $\mathrm{T} 1$ and T2. That is, the patients' W-M gap increased between T1 and T2. Interestingly, crosssectional comparison of TS patients with healthy controls revealed that neither the timing of judgements of the intention to move (W) and the movement itself $(\mathrm{M})$ nor the W-M gap as a parameter for volition differed between TS and control groups. This confirms the importance of a longitudinal approach for understanding the development of volition. Overall, the pattern of our results is consistent with a developmental change in discriminative perceptual learning of the different signals generated during voluntary action. For example, patients may become more able to discriminate an internal premotor signal corresponding to conscious intention, from the motor signals generated by action execution. Patients appear to learn a distinctive experience of volition during the course of adolescent development. We did not test a longitudinal healthy volunteer control group, so we cannot tell whether the developmental change in the TS patients' experience of volition is normal or abnormal. However, we were able to pool two samples of healthy participants of different ages. This showed cross-sectionally that the size of the W-M gap depends on age at time of testing.

Further, this developmental process of learning volition was related to the disease. Patients with shorter disease duration tended to have larger W-M gaps. This finding was necessarily based on exploratory analyses using disease duration as a covariate, since the planning of the initial study at T1 did not include the possible longitudinal element of further testing at T2.

Taken overall, these results have several implications for the development of volition. First, an increase in the W-M gap is a viable experimental proxy for the emergence of experience of volition during the course of adolescent development. Second, this process is apparently based 
on discriminative perceptual learning processes within the brain's cognitive, sensory and motor systems. Third, these processes are disrupted by TS, with longer disease durations leading to reduced emergence of the W-M gap.

Therefore, variability in disease duration contributed significantly to individual differences between patients in the W-M gap. When this source of variability was accounted for by including disease duration as a covariate, the effect size of the group-level change in the W-M gap between $\mathrm{T} 1$ and $\mathrm{T} 2$ was increased. These findings are consistent with the co-presence of two effects on the development of volition: an increase in the W-M gap during adolescent development, and a second factor linked to the presence of TS, which tends to counteract this increase. Perceptual learning to correctly distinguish and classify internal motor signals associated with volition appears to be progressively disturbed by TS. We suggest that tic-related noise in the motor system of TS patients compromises the emergence of a normal experience of volition.

Our study clearly raises the question whether the developmental increase in the W-M gap in TS patients is normal or pathological. Since we do not have longitudinal data from volunteers, we cannot definitively answer that question. However, we can investigate this point crosssectionally: the W-M gap in healthy controls was greater in the T2 sample than in our previously published T1 adolescent sample (-229.3ms $\pm 190.61 \mathrm{~ms}$ vs. $-117.43 \mathrm{~ms} \pm 81.26 \mathrm{~ms}$, respectively (Ganos, Asmuss, et al., 2015)). Further, linear regression indicated an increase in the W-M gap with age across the pooled samples. These findings are consistent with developmental maturation of anticipatory awareness for volition, allowing an improving perception of the distinctive signals that discriminate voluntary actions from other 'motor noise' (Ganos, Asmuss, et al., 2015). 
At first sight, the longitudinal data of TS patients showed only modest changes between T1 and T2, specifically in the W-M gap (see fig. 1B). This picture changed, when the disease duration was considered in exploratory analyses as a possible factor influencing the development of volition: patients with longer disease duration showed less increase in the W-M gap between $\mathrm{T} 1$ and T2. This suggests that perceptual learning to correctly distinguish and classify internal motor signals associated with volition is disturbed with increasing disease duration. One possible explanation might be that ongoing tics during the course of the disease create strong motor noise that masks perceptual learning and discriminative learning about the various sensorimotor signals that accompany voluntary actions. As we previously proposed, this perceptual difficulty might lead to secondary consequences and compensatory adjustments. For example, participants might choose a conservative selection criterion to correctly distinguish signals of volition from other internal motor signals, leading to a smaller W-M gap (Ganos, Asmuss, et al., 2015).

A previous study suggested that delayed experience of the intention to move in adult TS patients was associated with tic severity (Moretto et al., 2011). This association could neither be replicated in our dataset from 2015 (Ganos, Asmuss, et al., 2015), nor in a subset of those patients in this current study. One reason for the lack of correlation might be, that the current patient group was more homogeneous, and patients with highly severe cases of TS were missing (YGTSS-100 scores T1: $23.6 \pm 13.1$, range $4-52$, T2: $17.1 \pm 14.6$, range $0-54$ ), compared to the patient sample of Moretto et al. (YGTSS-100 scores: $43.8 \pm 13.5$, range $26-70$ ) (Moretto et al., 2011). Thus, our results do not preclude that volition might be poorly developed in patients with more severe TS. Further, patients of the Moretto et al. sample were much older (43.4 \pm 15 years vs. $19 \pm 2.4$ years) (Moretto et al., 2011), implying a longer disease duration. Thus, our present results encourage the speculation that development of volition might have been strongly compromised in the patients tested by Moretto et al. 
There is an ongoing debate regarding where tics should be allocated in the voluntaryinvoluntary spectrum of movement disorders. Unpleasant feelings or sensations (“premonitory urges") can motivate patients to execute a tic movement. The movement may then be perceived as involuntary, to the extent that it is compelled by an urge to tic. On the other hand, the decision to "give in" to the premonitory urge, and achieve relief by performing the tic, is mostly reported as voluntary decision (Cavanna, Andrea; Nani, Andrea, 2014). Interestingly, the experience of premonitory urges only develops a few years after the onset of tics in young children (Leckman et al., 1993). Thus, the experience of voluntary control over motor actions might change during the course of the disease, and might even differ between states of a single individual, since some tics may be preceded by premonitory urges and others may not (Leckman et al., 1993). Many previous studies of volition in TS focused on neural correlates of premonitory urges in adults. Although some earlier studies indicated a role for primary somatosensory cortex (Draganski et al., 2010), more recent behavioral evidence linked premonitory urges to interoceptive experience (Ganos, Garrido, et al., 2015). Consistent with this view, some neuroimaging studies proposed that insular cortex plays a key pathophysiological node in the perception of premonitory urges. This is consistent with an interpretation of premonitory urges as interoceptive experiences (Tinaz et al., 2015). Importantly, a functional network between the insular cortex and premotor areas related to tic generation has been identified (Rae et al., 2018; Tinaz et al., 2015). However, it remains unclear whether the strength of premonitory urges impedes the development of volition. In our study sample, those two variables (i.e, the PUTS score and the W-M gap at T2) did not show any correlation.

Our study has a number of limitations. First, the study itself is relatively small in size, particularly as some of the original participants were lost to follow-up. However, we note that the 11 patients lost to follow-up did not differ from those who participated at $\mathrm{T} 2$, in terms of 
age and disease severity. This suggests that attrition was not strongly selective. Second, we were not able to provide longitudinal data for healthy controls. However, we showed an increase in the W-M gap with age in a cross-sectional sample of healthy volunteers, suggesting a developmental progression in the capacity to perceptually discriminate a feeling of conscious intention from the experience of acting itself. Thus, the developmental change observed in the TS group may reflect a normal physiological change. We nevertheless showed that emergence of the W-M gap is strongly affected by disease duration in the TS group. Thus, development of the W-M gap in adolescent patients with TS was disturbed by the disease process. This final conclusion is based on analysis of covariance that is necessarily exploratory, because the longitudinal design was not envisaged when the T1 study was first planned. This raises the interesting question of whether a failure to develop a W-M gap has important clinical consequences. It remains unclear whether a large W-M gap for voluntary action is a central feature of TS, or is rather a secondary consequence or epiphenomenon of the tic disorder. Besides the data presented here, there is also evidence of altered volitional control in patients with obsessive-compulsive disorder (Takashima et al., 2019), a well-known comorbid disease of TS, possibly indicating a common pathophysiological mechanism. Finally, in a multifaceted disorder like TS, we cannot preclude the possibility that other factors such as the presence of psychiatric comorbidities, e.g. anxiety disorders (Silvestri et al., 2016), might have influenced the development of volition in our patients.

In conclusion, this is the first study to report longitudinal data on the development of volition from adolescence to adulthood in patients with TS. Our results suggest a growing gap between action and intention awareness, corresponding to the developmental emergence of the distinctive experience of one's own voluntary actions. This process is compromised in TS patients with increasing disease duration. This developmental difficulty in processing internal 
premotor signals for voluntary actions could reflect the chronic persistence of tics from adolescence to adulthood.

\section{References}

Beck, A. T., Ward, C. H., Mendelson, M., Mock, J., \& Erbaugh, J. (1961). An inventory for measuring depression. Archives of General Psychiatry, 4, 561-571.

Bloch, M. H., \& Leckman, J. F. (2009). Clinical course of Tourette syndrome. Journal of Psychosomatic Research, 67(6), 497-501. https://doi.org/10.1016/j.jpsychores.2009.09.002

Cavanna, A. E., Schrag, A., Morley, D., Orth, M., Robertson, M. M., Joyce, E., Critchley, H. D., \& Selai, C. (2008). The Gilles de la Tourette syndrome-quality of life scale (GTSQOL): development and validation. Neurology, 71(18), 1410-1416. https://doi.org/10.1212/01.wnl.0000327890.02893.61

Cavanna, Andrea; Nani, Andrea. (2014). Tourette Syndrome and Consciousness of Action. https://doi.org/10.7916/d8pv6j33

Christiansen, H., Kis, B., Hirsch, O., Philipsen, A., Henneck, M., Panczuk, A., Pietrowsky, R., Hebebrand, J., \& Schimmelmann, B. G. (2011). German validation of the Conners Adult ADHD Rating Scales-self-report (CAARS-S) I: factor structure and normative data. European Psychiatry: The Journal of the Association of European Psychiatrists, 26(2), 100-107. https://doi.org/10.1016/j.eurpsy.2009.12.024

Conners, C., Erhardt, D., Epstein, J., Parker, J., Sitarenios, G., \& Sparrow, E. (1999). Selfratings of ADHD symptoms in adults I: Factor structure and normative data. 3(3), $141-151$.

Delorme, C., Salvador, A., Voon, V., Roze, E., Vidailhet, M., Hartmann, A., \& Worbe, Y. (2016). Illusion of agency in patients with Gilles de la Tourette Syndrome. Cortex; a 
Journal Devoted to the Study of the Nervous System and Behavior, 77, 132-140. https://doi.org/10.1016/j.cortex.2016.02.003

Draganski, B., Martino, D., Cavanna, A. E., Hutton, C., Orth, M., Robertson, M. M., Critchley, H. D., \& Frackowiak, R. S. (2010). Multispectral brain morphometry in Tourette syndrome persisting into adulthood. Brain: A Journal of Neurology, 133(Pt 12), 3661-3675. https://doi.org/10.1093/brain/awq300

Eapen, V., Cavanna, A. E., \& Robertson, M. M. (2016). Comorbidities, Social Impact, and Quality of Life in Tourette Syndrome. Frontiers in Psychiatry, 7, 97. https://doi.org/10.3389/fpsyt.2016.00097

Frith, C. D. (1987). The positive and negative symptoms of schizophrenia reflect impairments in the perception and initiation of action. Psychological Medicine, 17(3), 631-648.

Ganos, C., Asmuss, L., Bongert, J., Brandt, V., Münchau, A., \& Haggard, P. (2015). Volitional action as perceptual detection: Predictors of conscious intention in adolescents with tic disorders. Cortex, 64, 47-54. https://doi.org/10.1016/j.cortex.2014.09.016

Ganos, C., Bongert, J., Asmuss, L., Martino, D., Haggard, P., \& Münchau, A. (2015). The somatotopy of tic inhibition: Where and how much? Movement Disorders: Official Journal of the Movement Disorder Society, 30(9), 1184-1189. https://doi.org/10.1002/mds.26188

Ganos, C., Garrido, A., Navalpotro-Gómez, I., Ricciardi, L., Martino, D., Edwards, M. J., Tsakiris, M., Haggard, P., \& Bhatia, K. P. (2015). Premonitory urge to tic in Tourette's is associated with interoceptive awareness. Movement Disorders: Official Journal of the Movement Disorder Society, 30(9), 1198-1202. https://doi.org/10.1002/mds.26228

Ganos, C., \& Martino, D. (2015). Tics and tourette syndrome. Neurologic Clinics, 33(1), 115136. https://doi.org/10.1016/j.ncl.2014.09.008 
Ganos, C., Münchau, A., \& Bhatia, K. P. (2014). The Semiology of Tics, Tourette's, and Their Associations. Movement Disorders Clinical Practice, 1(3), 145-153. https://doi.org/10.1002/mdc3.12043

Ganos, C., Pareés, I., \& Bhatia, K. P. (2015). Effort-Related Behaviors in Charcot's Lectures on Hysteria. Movement Disorders Clinical Practice, 2(2), 201-202. https://doi.org/10.1002/mdc3.12152

Ghosh, A., \& Haggard, P. (2014). The spinal reflex cannot be perceptually separated from voluntary movements: The spinal reflex and voluntary movements. The Journal of Physiology, 592(1), 141-152. https://doi.org/10.1113/jphysiol.2013.260588

Goetz, C. G., Pappert, E. J., Louis, E. D., Raman, R., \& Leurgans, S. (1999). Advantages of a modified scoring method for the Rush Video-Based Tic Rating Scale. Movement Disorders: Official Journal of the Movement Disorder Society, 14(3), 502-506.

Goodman, W. K., Price, L. H., Rasmussen, S. A., Mazure, C., Fleischmann, R. L., Hill, C. L., Heninger, G. R., \& Charney, D. S. (1989). The Yale-Brown Obsessive Compulsive Scale. I. Development, use, and reliability. Archives of General Psychiatry, 46(11), 1006-1011.

Groth, C., Mol Debes, N., Rask, C. U., Lange, T., \& Skov, L. (2017). Course of Tourette Syndrome and Comorbidities in a Large Prospective Clinical Study. Journal of the American Academy of Child and Adolescent Psychiatry, 56(4), 304-312. https://doi.org/10.1016/j.jaac.2017.01.010

Haggard, P. (2008). Human volition: towards a neuroscience of will. Nature Reviews. Neuroscience, 9(12), 934-946. https://doi.org/10.1038/nrn2497

Haggard, P. (2017). Sense of agency in the human brain. Nature Reviews. Neuroscience, 18(4), 196-207. https://doi.org/10.1038/nrn.2017.14

Haggard, P., Clark, S., \& Kalogeras, J. (2002). Voluntary action and conscious awareness. Nature Neuroscience, 5(4), 382-385. https://doi.org/10.1038/nn827 
Keller, I., \& Heckhausen, H. (1990). Readiness potentials preceding spontaneous motor acts: voluntary vs. involuntary control. Electroencephalography and Clinical Neurophysiology, 76(4), 351-361. https://doi.org/10.1016/0013-4694(90)90036-j

Kessler, R. C., Adler, L., Ames, M., Demler, O., Faraone, S., Hiripi, E., Howes, M. J., Jin, R., Secnik, K., Spencer, T., Ustun, T. B., \& Walters, E. E. (2005). The World Health Organization Adult ADHD Self-Report Scale (ASRS): a short screening scale for use in the general population. Psychological Medicine, 35(2), 245-256.

Leckman, J. F., Riddle, M. A., Hardin, M. T., Ort, S. I., Swartz, K. L., Stevenson, J., \& Cohen, D. J. (1989). The Yale Global Tic Severity Scale: initial testing of a clinicianrated scale of tic severity. Journal of the American Academy of Child and Adolescent Psychiatry, 28(4), 566-573. https://doi.org/10.1097/00004583-198907000-00015

Leckman, J. F., Walker, D. E., \& Cohen, D. J. (1993). Premonitory urges in Tourette's syndrome. The American Journal of Psychiatry, 150(1), 98-102. https://doi.org/10.1176/ajp.150.1.98

Libet, B., Gleason, C. A., Wright, E. W., \& Pearl, D. K. (1983). Time of conscious intention to act in relation to onset of cerebral activity (readiness-potential). The unconscious initiation of a freely voluntary act. Brain: A Journal of Neurology, 106 (Pt 3), 623642.

Mink, J. W. (2001). Basal ganglia dysfunction in Tourette's syndrome: a new hypothesis. Pediatric Neurology, 25(3), 190-198. https://doi.org/10.1016/s0887-8994(01)00262-4

Moretto, G., Schwingenschuh, P., Katschnig, P., Bhatia, K. P., \& Haggard, P. (2011). Delayed experience of volition in Gilles de la Tourette syndrome. Journal of Neurology, Neurosurgery, and Psychiatry, 82(12), 1324-1327. https://doi.org/10.1136/jnnp.2010.221143 
Poletti, M., Gebhardt, E., \& Raballo, A. (2017). Corollary Discharge, Self-agency, and the Neurodevelopment of the Psychotic Mind. JAMA Psychiatry, 74(11), 1169-1170. https://doi.org/10.1001/jamapsychiatry.2017.2824

Rae, C. L., Polyanska, L., Gould van Praag, C. D., Parkinson, J., Bouyagoub, S., Nagai, Y., Seth, A. K., Harrison, N. A., Garfinkel, S. N., \& Critchley, H. D. (2018). Face perception enhances insula and motor network reactivity in Tourette syndrome. Brain: A Journal of Neurology, 141(11), 3249-3261. https://doi.org/10.1093/brain/awy254

Retz-Junginger, P., Retz, W., Blocher, D., Weijers, H. G., Trott, G. E., Wender, P. H., \& Rössler, M. (2002). [Wender Utah rating scale. The short-version for the assessment of the attention-deficit hyperactivity disorder in adults]. Der Nervenarzt, 73(9), 830838. https://doi.org/10.1007/s00115-001-1215-X

Sambrani, T., Jakubovski, E., \& Müller-Vahl, K. R. (2016). New Insights into Clinical Characteristics of Gilles de la Tourette Syndrome: Findings in 1032 Patients from a Single German Center. Frontiers in Neuroscience, 10, 415. https://doi.org/10.3389/fnins.2016.00415

Silvestri, P. R., Chiarotti, F., Baglioni, V., Neri, V., Cardona, F., \& Cavanna, A. E. (2016). Health-related quality of life in patients with Gilles de la Tourette syndrome at the transition between adolescence and adulthood. Neurological Sciences: Official Journal of the Italian Neurological Society and of the Italian Society of Clinical Neurophysiology, 37(11), 1857-1860. https://doi.org/10.1007/s10072-016-2682-y

Takashima, S., Najman, F. A., \& Ramos, R. T. (2019). Disruption of volitional control in obsessive-compulsive disorder: Evidence from the Bereitschaftspotential. Psychiatry Research. Neuroimaging, 290, 30-37. https://doi.org/10.1016/j.pscychresns.2019.06.007

Tinaz, S., Malone, P., Hallett, M., \& Horovitz, S. G. (2015). Role of the right dorsal anterior insula in the urge to tic in Tourette syndrome. Movement Disorders: Official Journal 
of the Movement Disorder Society, 30(9), 1190-1197.

https://doi.org/10.1002/mds.26230

Ward, M. F., Wender, P. H., \& Reimherr, F. W. (1993). The Wender Utah Rating Scale: an aid in the retrospective diagnosis of childhood attention deficit hyperactivity disorder. The American Journal of Psychiatry, 150(6), 885-890. https://doi.org/10.1176/ajp.150.6.885

Wolpert, D. M., \& Flanagan, J. R. (2001). Motor prediction. Current Biology: CB, 11(18), R729-732.

Woods, D. W., Piacentini, J., Himle, M. B., \& Chang, S. (2005). Premonitory Urge for Tics Scale (PUTS): initial psychometric results and examination of the premonitory urge phenomenon in youths with Tic disorders. Journal of Developmental and Behavioral Pediatrics: JDBP, 26(6), 397-403. 


\section{Tables}

Table 1. Demographic and clinical characteristics of TS patients and healthy controls.

\begin{tabular}{|c|c|c|c|c|}
\hline & \multicolumn{2}{|l|}{ TS patients } & \multirow{2}{*}{\begin{tabular}{|l|} 
Controls \\
T2 \\
\end{tabular}} & \multirow{2}{*}{\begin{tabular}{|l|}
$\mathrm{p}$ \\
-
\end{tabular}} \\
\hline Time-point & $\mathrm{T} 1$ & $\mathrm{~T} 2$ & & \\
\hline Number, $\mathrm{n}$ & 16 & 16 & 16 & - \\
\hline Gender, male, n (\%) & \multicolumn{2}{|c|}{$14(87.5 \%)$} & $11(68.8 \%)$ & 0.394 \\
\hline Age, years & $13.5 \pm 2.4$ & $19 \pm 2.4$ & $19.1 \pm 2.6$ & 0.885 \\
\hline Beck's Depression Inventory & - & $7.6 \pm 7.5$ & $4.1 \pm 3.3$ & 0.289 \\
\hline Wender Utah Rating Scale & - & $19.6 \pm 16.3$ & $8.9 \pm 5.5$ & $0.031^{*}$ \\
\hline Symptoms of Inattention $^{1}$ & - & $3.2 \pm 2.3$ & $1.6 \pm 1.9$ & $0.032 *$ \\
\hline Symptoms of hyperactivity/ impulsivity ${ }^{1}$ & - & $2.7 \pm 2.4$ & $1.2 \pm 1.3$ & 0.074 \\
\hline Conner's Adult ADHD Rating Scale & - & $13.3 \pm 7.1$ & $10.7 \pm 4.2$ & 0.222 \\
\hline Y-BOCS, obsessive behaviour & - & $3.2 \pm 3.7$ & $0.3 \pm 0.5$ & $0.008^{*}$ \\
\hline Y-BOCS, compulsive behaviour & - & $4.8 \pm 4.3$ & $1.1 \pm 2.2$ & $0.014^{*}$ \\
\hline
\end{tabular}

\begin{tabular}{|c|c|c|c|c|}
\hline Yale Global Tic Severity Scale, 100, YGTSS-100 & $22.3 \pm 11.7$ & $17.1 \pm 14.6$ & - & 0.14 \\
\hline Yale Global Tic Severity Scale, 50, YGTSS-50 & $14.8 \pm 6.2$ & $12.1 \pm 7.3$ & - & 0.99 \\
\hline Premonitory Urges for Tics Scale, PUTS & $19.8 \pm 5.2$ & $20.2 \pm 5.9$ & - & 0.825 \\
\hline GTS-Quality of Life, GTS-QoL & $7.4 \pm 4.7$ & $12.2 \pm 9.6$ & - & $0.032^{\#}$ \\
\hline FBB-ADHS $^{2}$ & $0.9 \pm 0.6$ & - & - & - \\
\hline $\mathrm{CY}_{\mathrm{BOCS}}{ }^{2}$ & $8.1 \pm 6.9$ & - & - & - \\
\hline $\mathrm{CDRS}^{\mathrm{C}} \mathrm{R}^{2}$ & $23.2 \pm 5.7$ & - & - & - \\
\hline
\end{tabular}

Data is shown as mean \pm standard deviation, p-values indicate test statistics for comparisons between TS patients and healthy controls at T2 in the upper panel or between patients at $\mathrm{T} 1$ and 
T2 in the lower panel, ${ }^{1}$ according to the DSM-IV diagnostic criteria, ${ }^{2}$ these questionnaires are designed for children and therefore were used in the original study from 2015 (Ganos, Asmuss, et al., 2015), however were not applied in our current sample of adults at T2, *p < 0.05 (MannWhitney U test), ${ }^{\#} \mathrm{p}<0.05$ (paired samples t-test)

ADHD, attention deficit hyperactivity disorder, CY-BOCS, Children's Yale-Brown Obsessive Compulsive Scale, FBB-ADHS (Fremdbeurteilungsbogen für Aufmerksamkeits-/ Hyperaktivitätsstörungen (Döpfner, Görtz-Dorten \& Lehmkuhl, 2008), CDRS-R, Children’s Depression Rating Scale - Revised (Keller et al., 2011), TS, Tourette syndrome, Y-BOCS, Yale-Brown Obsessive Compulsive Scale

\section{Figures}

Figure 1. A. W- and M-judgements in TS patients and healthy controls at T2. Error bars indicate standard deviation. B. W- and M-judgements in TS patients at T1 and T2. Error bars indicate standard deviation. C. W- and M-judgements as a function of disease duration at T1 and T2. Note the only significant correlation in the upper right panel. D. Change of the W-M gap between T1 and T2 [(W2 - M2) - (W1 - M1)] as a function of disease duration. Smaller values on the $\mathrm{y}$-axis indicate an increasing $\mathrm{W}-\mathrm{M}$ gap at $\mathrm{T} 2 .{ }^{*} \mathrm{p}<0.05$ 


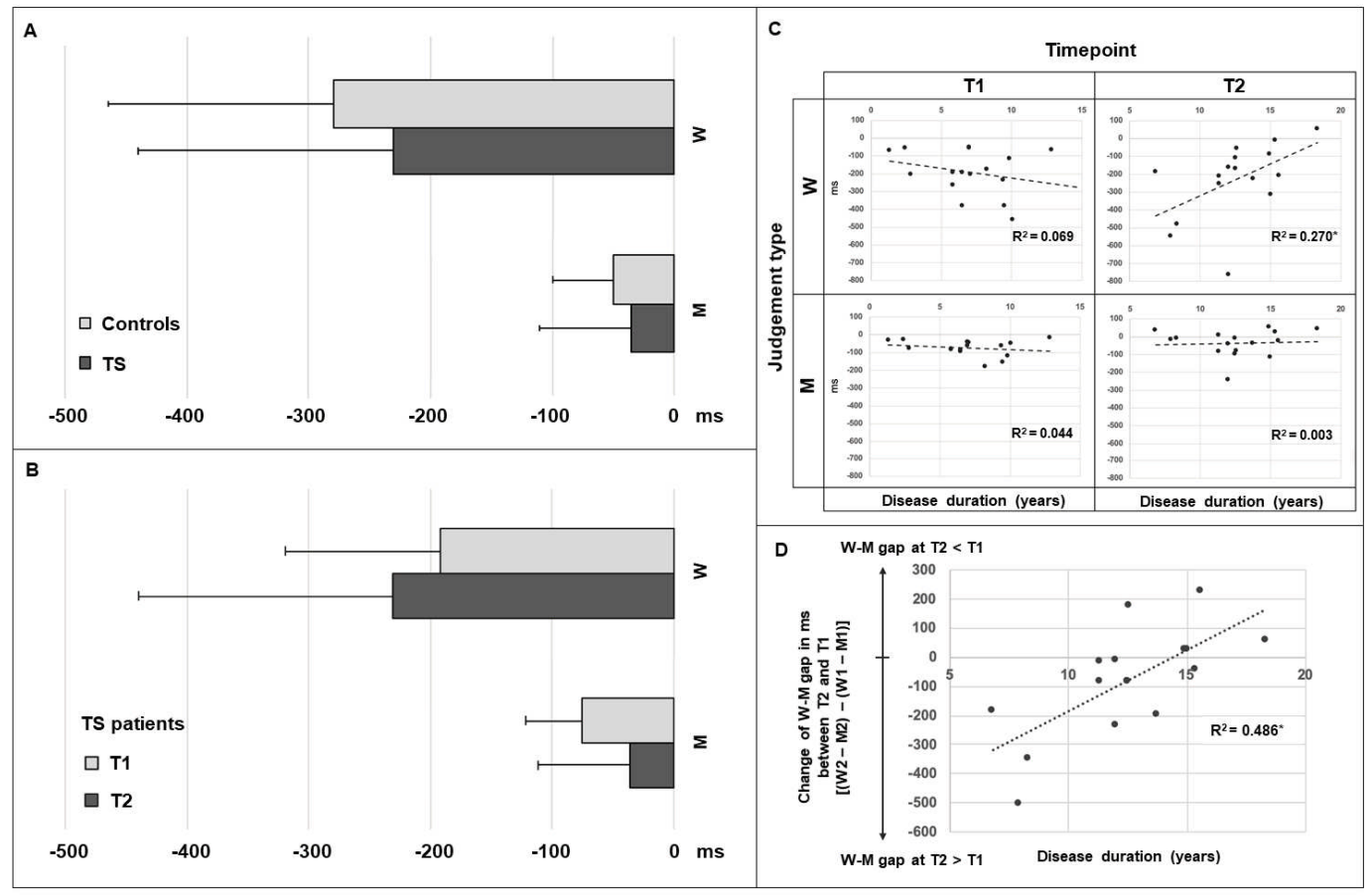

\section{Funding sources}

T.M. is supported by the BIH-Charité Clinician Scientist Program of the CharitéUniversitätsmedizin Berlin and the Berlin Institute of Health. F.B. is supported by the BIHCharité Clinician Scientist Program of the Charité-Universitätsmedizin Berlin and the Berlin Institute of Health. A.M. is supported by the Deutsche Forschungsgemeinschaft (DFG; FOR 2698 project numbers 396914663, 396577296, 396474989). C.G. is supported by a VolkswagenStiftung Fellowship (Freigeist) and also receives research support from Actelion Pharmaceuticals. P.H. is supported by a grant from the Leverhulme Trust (RPG-2016-378), by European Research Council (ERC) advanced grant HUMVOL (agreement 323943), and by a Chaire Blaise Pascal of the Région Île-de-France. 